\title{
An Online Survey on Job Satisfaction among Indian Radiologists - Under-Studied Journey from Promised Land to Paradise Lost
}

\author{
Sudha Kiran Das ${ }^{1}$, Vikram Patil2 ${ }^{2}$ Anupama Chandrappa ${ }^{3}$, \\ Sachin Thammegowda ${ }^{4}$, Sachin Prabhakar Shetty5, Rudresh Hiremath ${ }^{6}$ \\ 1, 2, 3, 4, 5, 6 Department of Radiodiagnosis, JSS Medical College and Hospital, Mysore, Karnataka, India.
}

\section{ABSTRACT}

\section{BACKGROUND}

Globally, radiodiagnosis is considered as one of the most sought after specialty in the field of medicine, based on the perceived notion that it is a high income, risk-averse, white-collared job. Radiologists are touted as being one of the highest paid specialists with defined work-hours; however, the ground reality appears to be in contradiction, particularly in the Indian context. The purpose of this study was to objectively assess the current day situation amongst the Indian radiologists. This gender-neutral survey not only dispels many of the prevailing assumptions but also brings to clear light the issues that assail the radiologist on a day to day basis.

\section{METHODS}

A cross-sectional descriptive study was performed with Google survey forms and collected data was obtained from 370 radiologists regarding various parameters, such as the workplace, years of experience, work hours per day, monthly income, peer, and work-related pressures, and their overall perceived happiness quotient. Issues concerning threats to radiology, the need for super or subspecialty training were also addressed.

\section{RESULTS}

Most of the young radiologists opted to work in either diagnostic centers or corporate hospitals as salary drawn was considerably higher than their counterparts in medical colleges. Nearly half the radiologists working at medical colleges augmented their income by working in diagnostic centers. Nearly $2 / 3^{\text {rds }}$ of the young radiologists work for an average of 10 hours per day, six days a week with a take home salary of approximately $1-2$ lakhs per month. Only $5 \%$ of the radiologists stated that they were most happy with their work environment, nearly $57 \%$ of them had some kind of occupational hazard and this was directly related to the years of work. Burn out predominated amongst the upcoming radiologists with less than 5 years of work experience and this was found to be compounded by work hours, work pressure and inadequate compensation.

\section{CONCLUSIONS}

Today, young radiologist is caught in a whirlpool of change that has not only threatened the "concept of a settled, satisfied, specialist", furtherance to this, commoditization of radiology has led to increase in work hours, work pressure, leading to dissatisfaction and early burn out.

\section{KEY WORDS}

Radiologist, Psychosocial Aspects, Burn Out, Artificial Intelligence.

\author{
Corresponding Author: \\ Dr. Anupama. $C$, \\ Department. of Radiodiagnosis, \\ JSS AHER, Mysuru, \\ Karnataka, India. \\ E-mail: anuvijay94@gmail.com
}

DOI: $10.14260 /$ jemds/2021/737

How to Cite This Article:

Das SK, Patil V, Chandrappa A, et al. An online survey on job satisfaction among indian radiologists: under-studied journey from promised land to paradise lost. J Evolution Med Dent Sci 2021;10(42):36333638, DOI: 10.14260/jemds/2021/737

Submission 07-06-2021,

Peer Review 04-08-2021,

Acceptance 10-08-2021,

Published 18-10-2021.

Copyright (C) 2021 Sudha Kiran Das et al. This is an open access article distributed under Creative Commons Attribution License [Attribution 4.0 International (CC $B Y 4.0)]$ 


\section{BACKGROUND}

Discovery of X-rays well over a century ago revolutionized the approach to diagnosis and therapy. Subsequent discoveries and exponential growth in the field of imaging technology underscored the need for specialists in this field. To start with, specialty training was merged with radiotherapy and it was well over half a decade that specialty courses were started in the field of diagnostic radiology. Over the years, this specialty has witnessed revolutionary changes in terms of technological advancements, emergence of artificial intelligence \& global unification via tele-radiology. ${ }^{1}$ Despite the formation of the Indian radiological association in 1931, the first MD radiology course in India was started in 1963 at Madras Medical College, humble beginnings with radiography and ultrasound. Today, one cannot undermine the all-pervasive nature and need of radiology which cuts across all medical specialties and has established itself as a cornerstone for diagnosis, evaluating therapeutic outcomes and in image-guided interventions.

Presently, the radiology training focus is into broad-based learning and there is a need to keep pace with the new developments in modern imaging. The need to sub-specialize has evolved over the last decade. ${ }^{1}$ Till date, radiology has remained as one of the most sought after specialty by top-rank graduate doctors opting for postgraduate specialty in India. In itself, radiology is considered to be an end specialty, with perks of higher income, opportunities, and job reputation. In a small cross-sectional descriptive study conducted in 2003 on 124 medical graduates who had graduated within the last 5 years from various government and private medical schools, majority (19 \%) of the students preferred to do post-graduation in specialty of radio-diagnosis and pediatrics. ${ }^{2}$

In the United States, radiologists are among the highest earning medical specialists but the same is not true for India. ${ }^{3}$ Lay public as well as non-radiology medical professionals misinterpret the income from the radiology business for the income of a radiologist. The global trend of radiologists being one among the highest paid specialists with defined work-hours does not appear to translate in toto to the Indian scenario. World over radiology is considered as one of the most sought after specialty in the field of medicine, however in the recent years, commoditization of radiology, the rise of other co-contesters in the field of imaging has resulted in turf wars, rise in litigation with consumer protection act has contributed greatly to burst the bubble of "Settled, Satisfied, and Specialist". The purpose of this gender neutral survey is to comprehend the ground scenario of a current day Indian radiologist with the intention to see the specialty in clear day light bereft of assumed perceptions.

\section{METHODS}

A cross-sectional descriptive study, was conducted as an anonymized online survey using Google survey forms during the month of January in the year 2019 by the Department of Radiodiagnosis, JSS Hospital and Medical College. The survey form was sent through e-mail and other online platforms like whatsapp, telegram, and facebook. Contact details were obtained from Indian radiological and imaging association (IRIA) platform and informed consent was obtained via the same platform. Clearance for the online survey was obtained from institutional ethical committee. Respondents of the survey included 375 practicing radiologists, out of them 5 had filled the survey form incompletely and were excluded. All 370 respondents who had completed the survey were included in the study. The online questionnaire was validated initially through a small pilot survey carried on practicing radiologists passed out from JSS institution. The questionnaire included queries regarding the workplace, volume and hours of work, income, mental health issues including burn out, ergonomics \& non-radiation occupational hazards, and others.

\section{Sample Size}

Sample size was calculated from online software at www.openepi.com. Population size was taken as 10,000 and hypothesized percentage frequency of outcome factor in the population was $50 \%+/-5$, Confidence limits as percentage of 100 was $5 \%$, design effect as sample size for $95 \%$ confidence level, thus calculated was 370 . The responses were statistically analyzed to evaluate for demographics, presence of various physical and mental health issues amongst the radiologists with reference to site of work, work hours and other key issues.

\section{Statistical Analysis}

Statistical analysis was performed using Statistical Package for Social Sciences (SPSS) software version 20 (IBM Inc., Armonk, New York, USA), Cramer's V co-efficient was calculated to measure the strength of association in addition to Pearson's coefficient.

\section{RESULTS}

Gender neutral online survey comprised of radiologists working across varied institutions with a wide range of experience. Of the 370 responses received, $72 \%$ were within 10 years of experience and $28 \%$ were with more than 10 years of experience. Majority of the respondents worked in diagnostic centers (37\%) of which $16 \%$ had self-owned diagnostic centers. Nearly $82 \%$ of radiologists working at medical colleges were also working at diagnostic centers, their work-hours ranged from 8 - 10 hours per day. Twenty six percent of the respondents were working at the corporate hospitals with work hours ranging from 6 - 8 hours per day. Few of them worked as teleradiologists $(2.2 \%)$ and $<1 \%$ of the radiologists were in government hospitals, missionary hospital, cardiac institutes and were visiting interventional radiology consultants (Figure 1). Current day radiologist clocks in approximately $8-10$ hours per day (46\%). A small subset (19\%) worked $>10$ hours per day, and all of them were either owners of diagnostic centers or intervention radiology consultants affiliated to different hospitals. Of concern, however was the association of income with occupational hazard and burn out (Cramer's V of 0.184 and 0.19 ) and this was directly proportional to the number of years of experience. Only a mere $9 \%$ had income greater than 4 lakhs per month and these were either owners of a private diagnostic centers owners or intervention radiologists with work experience of $>10$ years (Figure 1 ). 


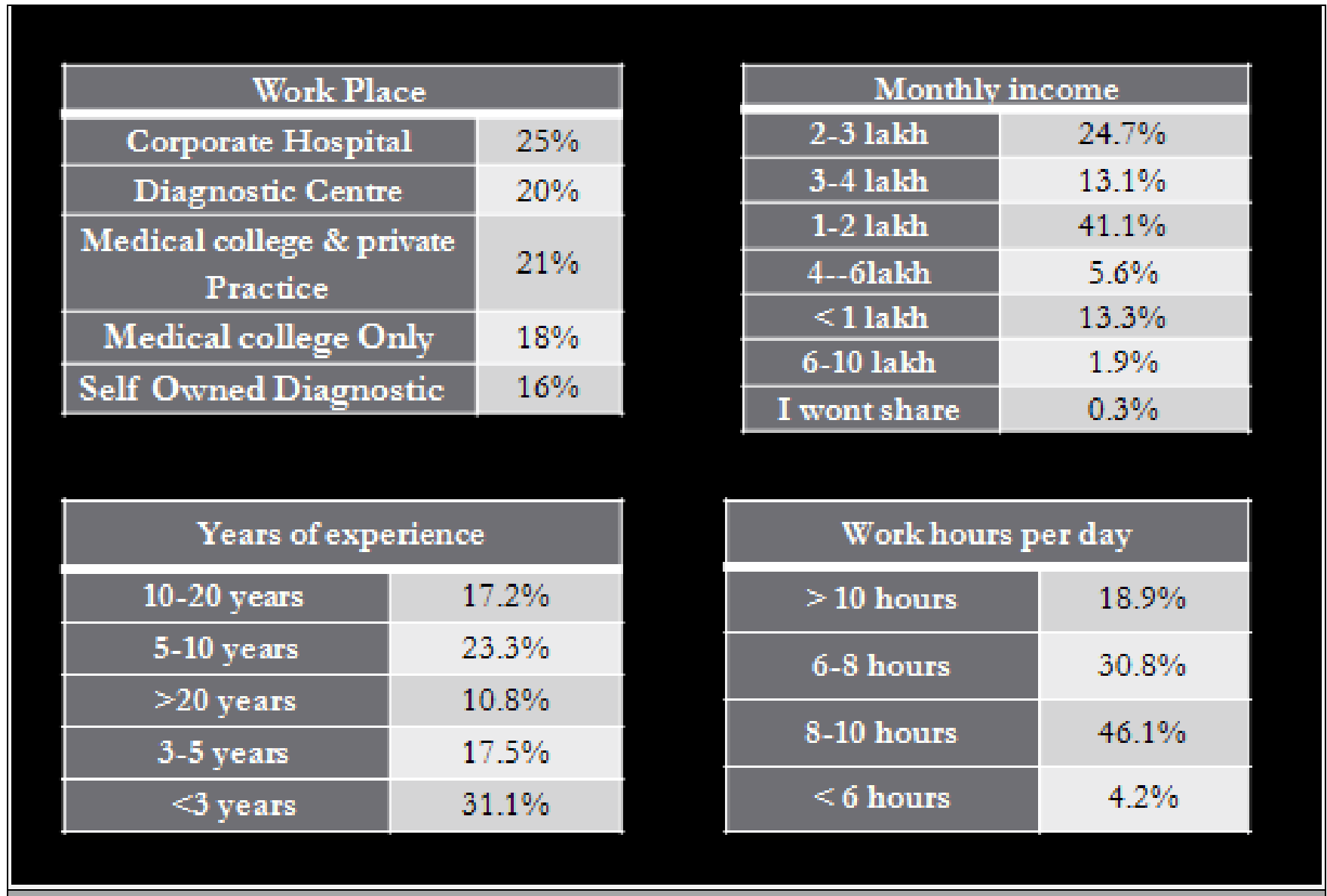

Figure 1. Work Experience, Monthly Income and Workplace Preferences of the Study Participants.

\begin{tabular}{|c|c|}
\hline Happiness quotient \\
\hline 1 & $7.2 \%$ \\
\hline 2 & $18.3 \%$ \\
\hline 3 & $43.3 \%$ \\
\hline 4 & $26.1 \%$ \\
\hline 5 & $5.0 \%$ \\
\hline
\end{tabular}

\begin{tabular}{|c|c|}
\hline \multicolumn{2}{|c|}{ Satisfaction with career choice } \\
\hline 1 & $5.28 \%$ \\
\hline 2 & $8.89 \%$ \\
\hline 3 & $25.00 \%$ \\
\hline 4 & $33.89 \%$ \\
\hline 5 & $26.94 \%$ \\
\hline
\end{tabular}

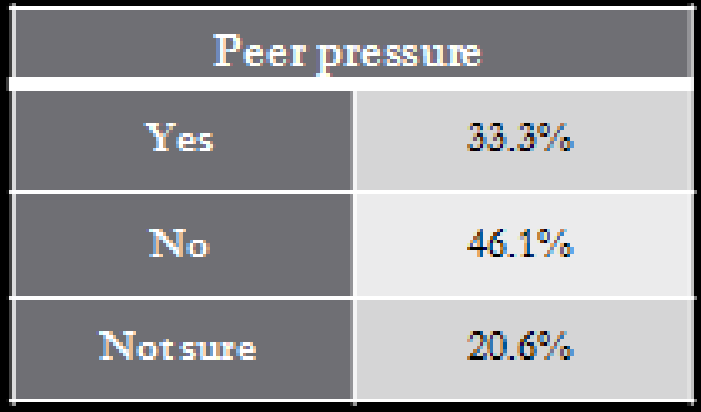

1-Least, 5-Highest 

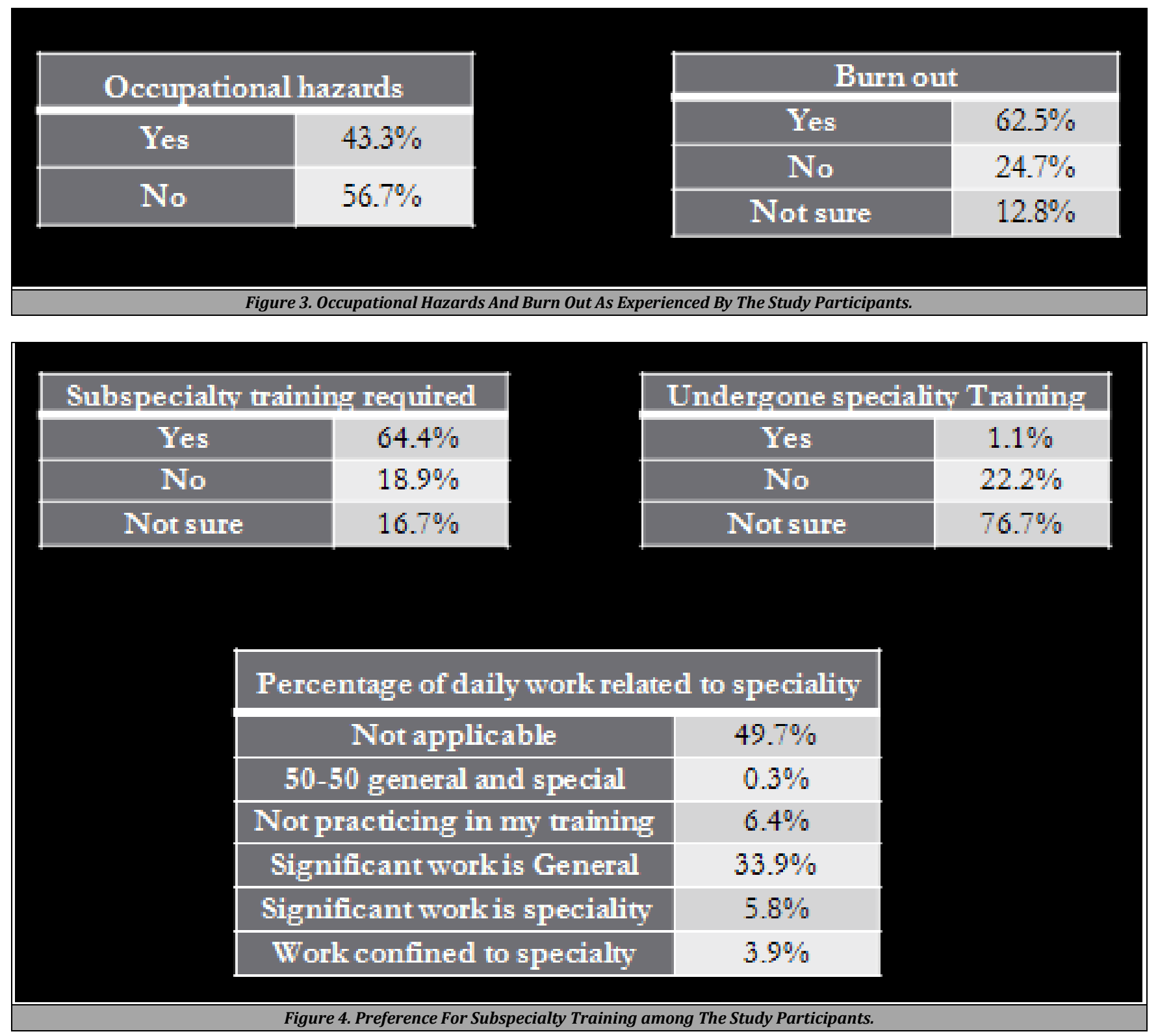

Despite the much touted pay-scales of radiologists, nearly $2 / 3^{\text {rd }}$ of the respondents had earnings between $1-3$ lakhs per month only; about half of them had an income of $1-2$ lakhs and majority of these were young radiologist clocking in approx. 8 - 10 hours of work per day. Only $5 \%$ of the radiologists said they are most happy with their work environment, while the majority of the respondents (43\%) rated their work environment as 3 out of 5 (Figure 2). Nearly $2 / 3$ rd's opined that work appreciation, better incomes, and good camaraderie (both among the radiologists and with other clinicians) would positively affect their work-related happiness quotient. Interestingly, entrant radiologists $(<5$ years) who were satisfied with work, were those affiliated to the corporate sector, defined work hours, job security and higher pay scales for entrant radiologists appeared to be the factors influencing this.

$27 \%$ of the radiologists said they are most happy with their career choice, the other $34 \%$ of respondents rated their work environment as 4 out of 5 , followed by $25 \%$ rated it 3 out of 5. Inadequate pay for the number of work-hours clocked in was one of the major determinants ( $42.2 \%$ ) contributing to diminished work satisfaction, with a Cramer's V of 0.38 .
Another factor was the possibility of medico-legal suits and threat of being maligned by media. Other factors that do play a role are target-oriented performance as practiced in the corporate sector, dichotomy and the attitude of the referring consultants.

$39 \%$ of radiologists expressed pressure at the work environment as 3 out of 5, and another $33 \%$ rated it at 4 out of 5 , a mere $4 \%$ felt the least pressure, the latter were affiliated to the medical colleges with $>10$ years of experience. About 47 (13\%) radiologists have rated work pressure as 5 out 5 . On the question of peer pressure, $46 \%$ of respondents felt that they had not experienced any pressure from other radiology colleagues (Figure 2). Statistically, peer pressure and work pressure related to income was unrelated to the place of work.

About $57 \%$ of the radiologists stated that they have suffered from some kind of occupational hazards like cervical spondylosis, carpal tunnel syndrome, and shoulder pain in their work environment. This correlates directly to the number of years of work experience and was found to the statistically significant with a $\mathrm{P}-$ value $<0.05 .62 \%$ of the respondents have experienced burnout at some point in time and nearly majority of the radiologists who have experienced 
burnout were $<5$ years of work experience (Figure 3). Stressbusters were music, travel, a small subset (18\%) resorted to outdoor games and reading.

Another interesting observation, regarding subspecialty or super specialty training, $64 \%$ of the respondents opined that it's a necessity while $19 \%$ have felt there was no need for such training. Although majority of the respondents felt the need for subspecialty or super specialty training, only $22 \%$ of the respondents had undergone some form of training while the rest had not undergone any formal training. Even among those who had undergone subspecialty or super specialty training, most of the respondents ( $68 \%$ ) said their significant work was general radiology and only $8 \%$ said their work was confined to their trained specialty (Figure 4).

The greatest threat to radiology today as perceived by the respondents was other specialists taking over radiology (42 $\%$ ), followed by corporate takeover of radiology as a business venture (29\%) and dichotomy (fee spitting - $17 \%$ ). Much touted as a threat to the radiologist, Artificial intelligence was not considered a threat by a vast majority, a mere $5 \%$ of the respondents felt it was a threat. Despite the odds, nearly $48 \%$ stated given a choice they would choose radiology again, while another $23 \%$ said they would opt-out of radiology as a choice for post-graduate studies.

\section{DISCUSSION}

The practice of medicine has seen a paradigm shift over the last two decades from evidence based medicine to the defensive practice of medicine, this being precipitated by the legal environment that encourages malpractice suits against health care workers. The medical fraternity over the years has not only had to cope with the knowledge boom and ever evolving practice of medicine but also has been under pressure due to the corporatization of healthcare.

In India, we have about 8.5 doctors $/ 10000$ population as per 2018 World Health Organization (WHO) statistics which is far less compared to a developed country like the United States of America which had about 26 doctors/10000 population in the year 2017.4 High population density and a huge burden of patients over a doctor in India pose a challenge to Indian health care worker. Looking into the scenario of Indian radiologists, they are about 10,000 in number, with a skewed ratio of $1: 100,000$ as opposed to the US ratio of $1: 10,000^{1}$ Despite being one of the most preferred branches in medicine, a questionnaire-based cross-sectional study recently conducted at Christian Medical College, Vellore, revealed that a mere $11 \%$ of undergraduate students chose radiology as one of their most likely preferred subject of post-graduation. ${ }^{2}$

The skewed ratio of MBBS to post graduate seats is another deterrent. Medical council of India (MCI) currently (2020) has recognized 542 medical institutes, with a total strength of 79,955 MBBS graduates per year. In the post MBBS level, there are about 42,123 broad and super specialty seats recognized by $\mathrm{MCI}$ and about a total of 9795 seats recognized by national board of examinations (NBE) which includes broad specialty, super specialty, and fellowship courses. Pertaining to radiology there are 291 primary diplomate of national board (DNB), 1854 MD in radio-diagnosis seats which have a course duration of 3 years, 291 secondary DNB (post diplomate in radiology), and 76 diplomate in radiodiagnosis seats with a duration of 2 years. ${ }^{5,6,7}$

To make a specialist in the field of medicine, it takes an average of 10 years, 5 years of MBBS and another 3 years for masters. Most undergraduates who get a post-graduation seat on a merit basis are from a middle-class background. Having already invested 8 to 10 years in educating themselves as a radiologist, they are very likely to settle themselves with a decently higher income job in private sector leaving behind their research and sub-specialty interests. ${ }^{3}$ This appears to be a great influencer in the choice of work place. This in addition to inability to procure placement in specialty institutes is also one of the deterrents for sub-specialization. ${ }^{5}$

$13 \%$ of them were working in medical colleges and were doing private practice in addition to their medical college work. Many of them worked 8 - 10 hours per day for a salary of 1 - 3 lakhs per month, on par with other broad specialties in India. A small subset earned more than 4 lakhs per month, in our study, all were private players, disproportionately high income of few radiologists are due to various reasons e.g., association with a successful hospital that has outsourced its radiology, presence in an untapped market, an exceptionally successful interventional practice, super specialty training etc. ${ }^{8}$ This too appears to be anecdotal as huge capital expenditure involved in CT scan and MRI set-ups and added fierce competition most centers following ethical practice manage to earn just enough to pay back their loans. ${ }^{8}$

A cordial working environment, reasonable working hours and a good compensation appeared to directly relate to work satisfaction. While most did have an interest in pursuit of academic excellence, hours at work, and burn out at the end of the day refrained them to do so. Most of them had chosen contentment, despite having experienced work pressure, burnout, physical fatigue, occupational hazards, and peer pressure at some point in time in their career.

Each radiologist in India ends up with the responsibility of imaging annually about 120,000 which is highly impracticable and on the flip side health of people in rural India is at stake due to a lack of imaging centers or a radiologist in their immediate vicinity. ${ }^{9}$ Radiological imaging data continues to grow at a disproportionate rate and given the skewed ratio of radiologists to the volume of radiological investigations, Artificial intelligence (AI) is a promising ray of hope particularly in a populated country like India. AI can aid the radiologist in varied ways, such as in routine repetitive tasks which can be cumbersome requiring minimal expertise, but also as a simple backup check for the diagnosis. ${ }^{10,11}$

The technological advances in the past and upcoming decade focusing on faster scans, thereby more number of investigations being done, over-utilization of imaging services secondary to defensive medicine, healthcare ventures being viewed as a business model with efficacy being assessed in terms of turn - over have led to early burnout.

\section{CONCLUSIONS}

The current day radiologist has ceased to be a mere spectator of the changes. They are caught in the storm of change that has threatened their own niche. The golden days of radiology are far gone causing the current day radiologist to rethink his 
career choice. In lieu of the above issues addressed in this study, the radiologist inevitably faces a distressing paradox, despite being one amongst the best and brightest medical students. Given the current day scenario, most are hesitant to convince the upcoming students as torch-bearers of tomorrow. As on date, the indian medical fraternity is quite aware of the number of super-specialty seats that are lapsing, unless a suitable intervention is made, it appears to be the road ahead for the field of radiology which could be detrimental to the healthcare scenario in India as a whole.

Data sharing statement provided by the authors is available with the full text of this article at jemds.com.

Financial or other competing interests: None.

Disclosure forms provided by the authors are available with the full text of this article at jemds.com.

\section{REFERENCES}

[1] Kalyanpur A. Commentary 3 - radiology in India: the next decade. Indian J Radiol Imaging 2008;18(3):191-2.

[2] Anand R, Sankaran PS. Factors influencing the career preferences of medical students and interns: a cross sectional, questionnaire - based survey from India. J Educ Eval Health Prof 2019;16:12.

[3] Sohoni CA. Do most radiologists in India really have a choice? Indian J Radiol Imaging 2015;25(2):207-8.
[4] World Health Organization. Density of Physicians (Total Number per 1000 Population, Latest Available Year), Global Health Observatory (GHO) Data. Situation and Trends. [Last accessed on 2018 Aug 10].

[5] Arora R. The training and practice of radiology in India: current trends. Quant Imaging Med Surg 2014;4(6):44950.

[6] List of colleges teaching MBBS and post graduate courses. [Last accessed on 2020 jun 8]. https://www.mciindia.org/CMS/informationdesk/college-and - course - search

[7] National board of examinations. https://accr.natboard.edu.in/online_user/frontpage.php $? \mathrm{v}=4$ [Last accessed on 2020 jun 8].

[8] Jankharia B. The business of radiology. Indian J Radiol Imaging 2010;20(4):239.

[9] Thapliyal A. Market expansion strategy for tele radiology services into resource-poor healthcare set-ups. International Journal of Scientific \& Engineering Research 2019;10(8):1246-59.

[10] Liew C. The future of radiology augmented with Artificial Intelligence: a strategy for success. Eur J Radiol 2018;102:152-6.

[11] Mahajan A, Vaidya T, Gupta A, et al. Artificial intelligence in healthcare in developing nations: the beginning of a transformative journey. Cancer Res Stat Treat 2019;2(2):182-9. 